\title{
The Effects of Different Diet Models on Oocyte Quality, Oocyte Maturation and in Vitro Fertilization Outcomes in Mice
}

\author{
Veysel TOPRAK ${ }^{1}$, Özcan BUDAK ${ }^{2 *}$, Mehmet KULHAN ${ }^{3}$, Hatice Esra CAN², Yasemin İSKEFIYELİ ${ }^{2}$ \\ 1.Private Tatvan Can Hospital Gynecology and Obstetrics, Bitlis 13200, Turkey Tel. \\ 2.Sakarya University, Faculty of Medicine, Histology and Embryology Department, Sakarya \\ 3.Selcuk University Medical Faculty, Gynaecology and Obstetrics Department, Konya, Turkey
}

\begin{abstract}
Nutritional quality affects fertility in both men and women. Nutrition should be considered in the prevention and treatment of infertility in men and women. In this study, we evaluated IVF rates, oocyte maturation and oocyte quality in a female animal model feding ketogenic, western and standard type diet. Female BALB / c mice were allocated to three groups: (a) control; (b) Western and (c) Ketogenic. After feeding female mice with these 3 feeding groups for 4 weeks, IVF was administered before sacrification of the mice. The number of collected oocytes and oocyte quality, fertilization rates and embryo quality were evaluated.The number of total oocytes was the highest in the ketogenic diet and the least in the western diet. MII stage oocytes in the ketogenic group were statistically significantly higher than the control group and western groups. Fertilized oocyte count was significantly lower in the western group compared to the other two groups. When the two-cell zygote stage was evaluated, it was found that the results were better in the ketogenic diet group and worse in the western diet group. The worst results in terms of the number of zygotes reaching the blastocyst stage were observed in the western type nutrition group, and the best results were observed in the group on the keteogenic diet. The results of our study show that western nutritional models negatively affect IVF results, while ketogenic diet has a positive effect.
\end{abstract}

Keywords: Fertility, ketogenic diet, oocyte, ovulation, western diet

DOI: $10.7176 / \mathrm{JMPB} / 72-02$

Publication date: January $31^{\text {st }} 2022$

\section{Introduction}

The diets of most expectant mothers who are planning to conceive are often inadequate. Nutrition, lifestyle factors, diet, exercise, stress, alcohol, drug use, smoking and obesity affect cycle performance during in vitro fertilization (IVF) treatments $(1,2)$. Studies have shown that nutritional quality affects fertility in both men and women (3). The success of IVF in embryology laboratories depends on the culture media used for embryo development. Oocyte quality, embryo development and the condition of the ovaries and endometrium, which are the main factors affecting the success of the treatment, depend on the physiology of the expectant mother. This has been demonstrated in many animal and human models in vivo $(4,5)$. The IVF treatment process depends not only on embryo culture, but also on oocyte hyperstimulation (OS) and the endometrium (6-8). Nutrition types, smoking, excessive weight, exercise and stress, as well as lifestyle factors, reduce the chance of pregnancy in IVF treatments (9). Nutrition should be considered in the prevention and treatment of infertility in men and women.

In studies conducted on overweight women with polycystic ovary syndrome (PCOS), it was observed that when their diets were enriched with proteins (30\% calcium enriched, $15 \%$ protein-based) circulating androgens decreased and menstrual cycle improved and insulin sensitivity increased as a result of weight loss (10-13). In these studies, it is thought that protein intake actually has no effect on reproductive function, however, changing dietary habits, namely preferring proteins instead of carbohydrates and reducing carbohydrate intake, may result in minor improvements in menstrual cycles due to a reduced insulin sensitivity. Although this result seems to be a small step, it could be a big step for pregnancy.

In our study, we aimed to investigate the effects of nutrition on the ovaries and endometrium in the female reproductive system in vivo and on oocyte and embryo development in vitro using different diet models. We think that this study will contribute to the determination of the effects of nutrition on the female reproductive system during IVF.

\section{Material method}

The study was conducted in Sakarya University SÜDETAM laboratory with the decision of Sakarya University experimental animals ethics committee on 06/05/2020 and numbered 26. Applications in all research animals are made according to the protocol of "The European Commission Directive 86/609 / ECC guideline" within the framework of ethical use. In our study, 21 female BALB / c mice that are sexually active and undergoing menstrual cycle were used. All of the mice were 3 months old and $20 \pm 5 \mathrm{~g}$ in weight. Animals in prooestrus and oestrus periods were determined with smear and included in the study. Mice were housed in cages (seven per 
cage) standard conditions - 12 hours light, 12 hours dark, $60 \% \pm 5 \%$ humidity, $30{ }^{\circ} \mathrm{C} \pm 2{ }^{\circ} \mathrm{C}$ temperature, easy access to food and water - for 4 weeks. Then the mice split in three groups:

1. Control Group (CG) (7 mice): 4 weeks standard feeding group ,

2. Ketogenic Group (KG) (7 mice): 4-weeks ketogenic type feding group

3. Western Group: (WG) (7 mice): 4-weeks western-type feeding group

Three diets pattern ingredients are summarized in Table 1. The energy received by each group of mice was measured by weighing the mice weekly.

After feeding female mice with these 3 feeding groups for 4 weeks, IVF was administered before sacrification of the mice. The number of collected oocytes and oocyte quality were evaluated by aspirating oocytes from female mice on the day of sacrifice. On the same day, oocytes were processed using the sperm of one male mice. Oocytes were cultured to evaluate fertilization and embryo quality.

\subsection{Stimulation and Collection of Oocytes}

Ovaries of female rats were stimulated by intraperitoneal (IP) application. Female rats in each group were superovulated with $15 \mathrm{IU}$ pregnant mare serum gonadotropin (PMSG). The superovulation protocol was completed by performing the second injection with 15 IU Human Chorionic Gonadotropin (HCG) hormone 48 hours after the first injection. About 10 to 12 hours after the second injection, the rats were sacrificed and oocytes were collected from the oviduct with an insulin injection. The number of oocytes we collected from each group was noted. Thus, the total number of oocytes belonging to different feeding groups was determined. For the incubation of oocytes, Human Tubal Fluid (HTF) medium with $4 \mathrm{mg} / \mathrm{ml}$ Human Serum Albumin (HSA) additive was cultured in an incubator at $37 \mathrm{deC}, 5 \% \mathrm{CO} 2$ concentration, one day before.

\subsection{Preparation of Oocytes and Maturation Assessment}

Before separating the oocytes from cumulus cells, they were incubated in culture medium (Global for fertilization, LifeGlobal, Guilford, USA) at $37^{\circ} \mathrm{C}$ for approximately 2 hours, covered with paraffin oil (Paraffin oil P.G. LifeGlobal). Most of the cumulus cells were removed from oocytes by keeping them in Hepes medium containing hyalurinidase ( $80 \mathrm{IU} / \mathrm{ml}$, LifeGlobal) enzyme. The remaining cumulus cells were removed with the help of a glass pasteur pipette (Humagen Fertility Diagnostics, Charlottesville, USA). Oocytes made ready for maturation assessment. Oocyte maturation was assessed by detecting cumulus-free oocytes at $400 \mathrm{X}$ magnification under an inverted microscope (Eclipse TE 300 microscope, Nikon, Tokyo, Japan). Oocytes were evaluated as mature (in MII phase) if observed with the first polar body. We detected incomplete maturation oocytes by identifying metaphase I (MI) and germinal vesicle (GV) oocytes (14).

\subsection{Sperm Preparation}

Before oocytes were collected, a mixture of $75 \mathrm{mg} / \mathrm{kg}$ ketamine (Alfasan, Woerden, The Netherlands) and 10 $\mathrm{mg} / \mathrm{kg}$ xylazine (Rotexmedica, Tritau, Germany) was applied IP to a male rat and euthanized. After euthanasia was performed, the male reproductive system was surgically opened from the abdomen, the left and right epididymis were separated from the testicles and transferred to HTF medium containing $1 \mathrm{ml}$ HTF (Sigma, St. Louis, USA) and $4 \mathrm{mg} / \mathrm{ml}$ bouvine serum albumin (BSA). The epididymis were stripped with the help of forceps, the sperm were transferred into petri dishes and incubated at $37{ }^{\circ} \mathrm{C}$ for 30 minutes before in vitro fertilization (15).

\subsection{Insemination and Embryo Culture}

Oocytes and capacitated sperms were transferred to fertilization drops. Fertilization was controlled and the fertilized oocytes were washed and transferred to culture drops. Zygotes formed after fertilization were cultured for up to five days at $37^{\circ} \mathrm{C}$ in $6.0 \mathrm{CO} 2,5.0 \mathrm{O} 2$ incubators. Embryo development and blastocyst rates were compared and embryos were followed up to the blastocyst stage (14).

\section{Statistical analysis}

The software SPSS 22.0 was employed for the statistical analysis (SPSS Inc., Chicago, IL). Descriptive statistical methods: mean, standard deviation were obtained. Differences among the three groups were evaluated with oneway Anova and Tuckey analysis. $\mathrm{p}<0.05$ and $\mathrm{p}<0.01$ were taken as significance levels.

\section{Results}

At the end of 4 weeks, the mean weight gain of the mice was $0.471 \mathrm{~g} \pm 0.4786 \mathrm{~g}$ in the CG group, $0.686 \mathrm{~g} \pm$ 0.3388 in the KG group and $1.5 \mathrm{~g} \pm 0.4041 \mathrm{~g}$ in the WG group. There was a significant difference between the groups in terms of weight gain $(p<0.001)$. However, there was no significant difference between initial and final weights (Table 2).

Table 3 and graphic 1 shows the number of oocytes maturing to the MII stage during IVF, as well as the 
number of MI stage and GVs after 24 hours of culture. The number of total oocytes was the highest in the ketogenic diet and the least in the Western diet $(\mathrm{p}<0.01)$. MII stage oocytes in the KG group were statistically significantly higher than the CG and WG groups $(\mathrm{p}<0.01)$. When $\mathrm{CG}$ and $\mathrm{WG}$ groups were compared in terms of MII stage oocytes, the number of MII oocytes was found to be higher in favor of the CG group. however, this difference was not statistically significant $(\mathrm{p}>0.05)$. There was no significant difference between the groups in terms of MI stage oocyte count and germinal vesicle count.

When the IVF outcomes were examined, it was obviously found that the number of fertilized oocytes was higher in CG. Fertilized oocyte counts were 3.286 $\pm 0.4880,6.286 \pm 0.7559,2.714 \pm 0.9512$ in CG, KG and WG groups, respectively. Fertilized oocyte count was significantly lower in the WG group compared to the other two groups $(\mathrm{p}<0.01)$. When the two-cell zygote stage was evaluated, it was found that the results were better in the ketogenic diet group and worse in the western diet group $(\mathrm{p}<0.01)$. Two-cell zygote count were 2.571 \pm 0.5345 , $5.286 \pm 0.7559,2.429 \pm 0.9759$ in $\mathrm{CG}, \mathrm{KG}$ and $\mathrm{WG}$ groups, respectively. The worst results in terms of the number of zygotes reaching the blastocyst stage were observed in the western type nutrition group, and the best results were observed in the group on the keteogenic diet $(p<0.01)$. IVF outcomes and regarding oocyte quality are summarized in Table 3 .

\section{Discussion}

In the past, various foodstuffs have been used to increase fertility, and even today the diet is often seen as a potential fertility enhancer. A low-risk, easily accessible, easy-to-administer and potentially high-impact treatment attracts high interest among patients and physicians. This study examined whether a specific diet, such as a diet that targets specific macronutrient components of daily caloric intake, would be beneficial in IVF treatment and oocyte quality. Specifically, we reviewed the evidence in female animal model of ketogenic and western diets successfully used to treat other diseases. In a study involving about 19,000 women, researchers found a relationship between the amount of carbohydrates consumed and the risk of ovulatory infertility. $78 \%$ more ovulatory infertility was detected in women who consumed high levels of carbohydrates (16). In another study published a year before this study showed that animal protein consumption was associated with a $20 \%$ higher risk of ovulatory infertility, while vegetable protein consumption was associated with a $43 \%$ lower risk (17). These interesting findings suggest that obesity alone may not be responsible for subfertility and that certain dietary components may increase or impair reproductive potential. In this study, we evaluated IVF rates, oocyte maturation and oocyte quality in a female animal model feding ketogenic, western and standard type diet. This animal study, which includes ketogenic and western diets together, is the first study in the literature to our knowledge.

Ketogenic diet (KD), as the name suggests, increases the endogenous levels of ketone bodies by changing the physiological energy production towards ketosis. In a typical KD, high-carbohydrate foods are reduced while high-fat foods such as cream and butter are increased. Fats are used instead of carbohydrates as the primary energy source for those who practice this diet and thus a physiological hunger state is created in the body (18). In a study conducted in overweight and obese women with PCOS, it was found that KD resulted in a $12 \%$ improvement in total body weight and a 54\% improvement in fasting insulin. At 24 weeks of the study, $40 \%$ of patients completed the study and became pregnant spontaneously (19). However, KD has potential benefits as well as potential risks on ovulation. Chavarro and colleagues showed that women who consume significant amounts of trans-unsaturated fat are at an almost 2-fold higher risk for ovulatory dysfunction (20). Also, in an animal study showed that mice fed a high-fat diet displayed increased anovulation and decreased in vivo fertilization rates compared to mice fed a standard diet (21). The mainstay of the fertility traits of KD relates to the degree of weight loss achieved. The putative mechanism for these therapeutic effects is controversial, but they are probably multifaceted. In the present study, KD was eucaloric and designed to prevent weight loss. Even though the effect of KD on weight and fertility appears to be associated with the degree of caloric restriction, ketosis or increased metabolic activity, this has not yet been proven. In this study, IVF results show that dietary pattern affects both the quality and quantity of oocytes. Compared with CG and the WG, there were more MII oocytes and more fertilized oocytes differentiating into the two-cell zygote stage in the KG. All these observed changes affect fertility positively.

The western-style diet, also called the meat-dessert diet, is a diet that includes high amounts of red meat, sugary sweets, high-fat foods, and refined grains, chosen by many in developed and developing countries (22). High-fat dairy products, high-sugar drinks and higher processed meat intakes are also among the ingredients of the western diet. Excessive intake of carbohydrates has been associated with an increased risk of ovulatory infertility in a large cohort of women. in the Nurses' Health Study II (NHS II) (16). Interestingly, among the same women, higher protein intake has been found to lead to ovulatory infertility (17). This latter association was mainly due to animal protein intake, which showed a direct association with ovulatory infertility, whereas the association of vegetable protein with the same result was not statistically significant. These findings were consistent with our study. The NHS-II study found that taking one additional serving of meat, while keeping the 
daily calories intake constant, resulted in a $32 \%$ increase $(95 \% \mathrm{CI}, 8-62 \%)$ in the risk of ovulation infertility (17). In a study by Chaffin et al, healthy adult female rhesus macaques were fed typical western-type food for 6 months. Then, these animals and control animals fed a standard diet were subjected to the IVF procedure. An extremely low proportion of mature oocytes was detected in monkeys fed high sugar, $18.5 \%$ versus $86 \%$, respectively, compared to the standard diet group (23). The results of this study were consistent with our study. It is surprising that weight gain, which is likely to cause this difference, is not observed in monkeys fed the western diet. Also, in the our study, no difference was found between initial and final weights of the mices. While WD can be a good source for protein and other essential nutritional products, it also contains high levels of saturated fat and also contains hormonal residues, antibiotics, and negative effects that may occur due to processing red meat. Similarly, in a study by Braga et al, it was found that red meat consumption before IVF negatively affected embryo development and the possibility of pregnancy. This result was also consistent with our study (24).

This study has some limitations. First limitation is the lack of information regarding the feeding pattern of the sperm retrieved male mice, which may affect the results. Second, data from animal studies may not reflect the same results in humans.

\section{Conclusion}

This study investigated the effect of different dietary models on oocyte quality and IVF outcomes. The results of our study show that western nutritional models negatively affect IVF results such as the number of total oocyte, MII satege oocye, GV, fertilized oocyte, two-cell zygote and blastocyte counts; On the other hand, it was found that KD provided improvement in all these parameters

Conflict of Interest: The authors declare that they have no conflict of interest.

\section{References}

1. Anderson K, Norman RJ, Middleton P. (2010) Preconception lifestyle advice for people with subfertility. The Cochrane database of systematic reviews. (4):Cd008189.

2. Szamatowicz (2016) M. Assisted reproductive technology in reproductive medicine - possibilities and limitations. Ginekologia polska. 2016;87(12):820-3.

3. Gardiner PM, Nelson L, Shellhaas CS, Dunlop AL, Long R, Andrist S, et al.( 2008) The clinical content of preconception care: nutrition and dietary supplements. Am J Obstet Gynecol.;199(6 Suppl 2):S345-56.

4. Fleming TP, Kwong WY, Porter R, Ursell E, Fesenko I, Wilkins A, et al. (2004) The embryo and its future. Biology of reproduction.;71(4):1046-54.

5. Santos MA, Kuijk EW, Macklon NS.( 2010) The impact of ovarian stimulation for IVF on the developing embryo. Reproduction (Cambridge, England).;139(1):23-34.

6. Klemetti R, Sevón T, Gissler M, Hemminki E.( 2010) Health of children born after ovulation induction. Fertility and sterility.;93(4):1157-68.

7. Pelinck MJ, Hadders-Algra M, Haadsma ML, Nijhuis WL, Kiewiet SM, Hoek A, et al. (2010) Is the birthweight of singletons born after IVF reduced by ovarian stimulation or by IVF laboratory procedures? Reproductive biomedicine online.;21(2):245-51.

8. Ombelet W, Martens G, De Sutter P, Gerris J, Bosmans E, Ruyssinck G, et al.( 2006) Perinatal outcome of 12,021 singleton and 3108 twin births after non-IVF-assisted reproduction: a cohort study. Human reproduction (Oxford, England).;21(4):1025-32.

9. Dechanet C, Anahory T, Mathieu Daude JC, Quantin X, Reyftmann L, Hamamah S, et al(.2011) Effects of cigarette smoking on reproduction. Human reproduction update.;17(1):76-95.

10. Stamets K, Taylor DS, Kunselman A, Demers LM, Pelkman CL, Legro RS.( 2004) A randomized trial of the effects of two types of short-term hypocaloric diets on weight loss in women with polycystic ovary syndrome. Fertility and sterility.;81(3):630-7.

11. Moran LJ, Noakes M, Clifton PM, Tomlinson L, Galletly C, Norman RJ. (. 2003) Dietary composition in restoring reproductive and metabolic physiology in overweight women with polycystic ovary syndrome. The Journal of clinical endocrinology and metabolism;88(2):812-9.

12. Dravecka I, Lazurova I, Kraus V. (2003) Obesity is the major factor determining an insulin sensitivity and androgen production in women with anovulary cycles. Bratislavske lekarske listy.;104(12):393-9.

13. Bialka-Kosiec AA, Wilk K, Pytel M, Skrzypulec-Plinta V, Stojko R, Drosdzol-Cop A.( 2019) Body mass composition and dietary habits in adolescents with polycystic ovary syndrome. Ginekologia polska.;90(10):589-95.

14. Baker H, Lindsey J, Weisbroth(2006) 2nd S. The Laboratory rat 2nd ed. New York: Academic Press;.

15. Seed J, Chapin RE, Clegg ED, Dostal LA, Foote RH, Hurtt ME, et al. ( 1996) Methods for assessing sperm motility, morphology, and counts in the rat, rabbit, and dog: a consensus report. Reproductive toxicology.;10(3):237-44. 
16. Chavarro JE, Rich-Edwards JW, Rosner BA, Willett WC (2009). A prospective study of dietary carbohydrate quantity and quality in relation to risk of ovulatory infertility. European journal of clinical nutrition.;63(1):78-86.

17. Chavarro JE, Rich-Edwards JW, Rosner BA, Willett WC (2008) . Protein intake and ovulatory infertility. Am J Obstet Gynecol.;198(2):210.e1-7.

18. Freeman JM, Kossoff EH, Hartman AL(2007). The ketogenic diet: one decade later. Pediatrics.;119(3):53543.

19. Mavropoulos JC, Yancy WS, Hepburn J, Westman EC(2005). The effects of a low-carbohydrate, ketogenic diet on the polycystic ovary syndrome: a pilot study. Nutrition \& metabolism.;2:35.

20. Chavarro JE, Rich-Edwards JW, Rosner BA, Willett WC(2007). Dietary fatty acid intakes and the risk of ovulatory infertility. The American journal of clinical nutrition.;85(1):231-7.

21. Cordier AG, Léveillé P, Dupont C, Tarrade A, Picone O, Larcher T, et al (2013). Dietary lipid and cholesterol induce ovarian dysfunction and abnormal $\mathrm{LH}$ response to stimulation in rabbits. PloS one.;8(5):e63101.

22. Nazni P. (. 2014) Association of western diet \& lifestyle with decreased fertility. The Indian journal of medical research;140 Suppl(Suppl 1):S78-81.

23. Chaffin CL, Latham KE, Mtango NR, Midic U, VandeVoort CA(2014) . Dietary sugar in healthy female primates perturbs oocyte maturation and in vitro preimplantation embryo development. Endocrinology.;155(7):2688-95.

24. Braga DP, Halpern G, Setti AS, Figueira RC, Iaconelli A, Jr., Borges E, Jr. (2015) The impact of food intake and social habits on embryo quality and the likelihood of blastocyst formation. Reproductive biomedicine online.;31(1):30-8.

Table 1: Diet ingredients

\begin{tabular}{|l|c|c|c|}
\hline & Standard Diet & Ketogenic Diet & Western Diet \\
\hline Nutrient Information & \% kcal from & \% kcal from & \% kcal from \\
\hline Protein & 25.0 & 19.53 & 19.53 \\
\hline Carbohydrate & 58.0 & 4.95 & 39.70 \\
\hline Fat & 17.0 & 74.24 & 39.51 \\
\hline Others & - & 1.28 & 1.26 \\
\hline
\end{tabular}

Table 2: Mean weight of mice in groups

\begin{tabular}{|l|l|l|l|l|l|}
\hline \multirow{2}{*}{ Variable } & \multicolumn{3}{|c|}{ Mean \pm standart deviation } & \multirow{2}{*}{$\begin{array}{l}\text { P- } \\
\text { value* }\end{array}$} & \multirow{2}{*}{ p-value $^{* *}$} \\
\cline { 2 - 5 } & Control group & Ketogenic group & Western group & \\
\hline 1st week weight $(\mathrm{g})$ & $16.34 \pm 0.85$ & $16.42 \pm 0.37$ & $15.94 \pm 0.62$ & 0.346 & \\
\hline 2nd week weight $(\mathrm{g})$ & $16.37 \pm 0.59$ & $16.64 \pm 0.26$ & $16.20 \pm 0.63$ & 0.311 & \\
\hline 3rd week weight $(\mathrm{g})$ & $16.55 \pm 054$ & $16.85 \pm 0.26$ & $16.87 \pm 0.390$ & 0.305 & \\
\hline 4th week weight (g) & $16.81 \pm 0.52^{\mathrm{a}}$ & $17.10 \pm 0.24$ & $17.44 \pm 0.47^{\mathrm{a}}$ & 0.045 & $\mathrm{P}^{\mathrm{a}}=0.036$ \\
\hline Weight gain (g) & $0.47 \pm 0.47^{\mathrm{a}}$ & $0.68 \pm 0.33^{\mathrm{b}}$ & $1.50 \pm 0.40^{\mathrm{a}, \mathrm{b}}$ & 0.000 & $\begin{array}{l}\mathrm{P}^{\mathrm{a}}=0.001, \\
\mathrm{p}^{\mathrm{b}}=0.004\end{array}$ \\
\hline
\end{tabular}

*Data was analysed using oneway anova test

**Data was analysed using Tukey HSD test

Pa Comparison between control and western group

$\mathrm{Pb}$ Comparison between ketogenic and western group $p$ value of $<0.05$ was considered statistically significant. 
Table 3: Number of Total oocytes, MII stage oocyte, MI stage oocyte, Germinal vesicle, Fertilized oocyte count, Two-cell zygote and Blastocyst count.

\begin{tabular}{|c|c|c|c|c|c|}
\hline \multirow[t]{2}{*}{ Variable } & \multicolumn{3}{|c|}{ Mean \pm standart deviation } & \multirow[t]{2}{*}{ P-value* } & \multirow[t]{2}{*}{ p-value e* $^{* *}$} \\
\hline & Control group & $\begin{array}{l}\text { Ketogenic } \\
\text { group }\end{array}$ & $\begin{array}{l}\text { Western } \\
\text { group }\end{array}$ & & \\
\hline Total oocyte & $6.857 \pm 0.6901^{\mathrm{a}, \mathrm{b}}$ & $8.714 \pm 0.4880^{\mathrm{a}, \mathrm{c}}$ & $5.286 \pm 0.7559^{b, c}$ & 0.000 & $\begin{array}{l}\mathrm{p}^{\mathrm{a}}=0.000, \quad \mathrm{p}^{\mathrm{b}}=0.001, \\
\mathrm{p}^{\mathrm{c}}=0.000\end{array}$ \\
\hline MII oocyte & $4.571 \pm 0.5345^{\mathrm{a}}$ & $7.429 \pm 0.5345^{\mathrm{a}, \mathrm{c}}$ & $3.571 \pm 1.1339^{\mathrm{c}}$ & 0.000 & $\mathrm{p}^{\mathrm{a}}=0.000, \mathrm{p}^{\mathrm{c}}=0.000$ \\
\hline MI oocyte & $1.429 \pm 0.5345$ & $1.143 \pm 0.6901$ & $1.143 \pm 0.3780$ & 0.543 & \\
\hline GV oocyte & $0.857 \pm 0.3780^{\mathrm{a}}$ & $0.143 \pm 0.3780^{\mathrm{a}}$ & $0.571 \pm 0.5345$ & 0.022 & $\mathrm{p}^{\mathrm{a}}=0.018$ \\
\hline $\begin{array}{l}\text { Fertilized } \\
\text { oocyte }\end{array}$ & $3.286 \pm 0.4880^{\mathrm{a}}$ & $6.286 \pm 0.7559^{\mathrm{a}, \mathrm{c}}$ & $2.714 \pm 0.9512^{\mathrm{c}}$ & 0.000 & $\mathrm{p}^{\mathrm{a}}=0.000, \mathrm{p}^{\mathrm{c}}=0.000$ \\
\hline Two-cell zygote & $2.571 \pm 0.5345^{\mathrm{a}}$ & $5.286 \pm 0.7559^{\mathrm{a}, \mathrm{c}}$ & $2.429 \pm 0.9759^{c}$ & 0.000 & $\mathrm{p}^{\mathrm{a}}=0.000, \mathrm{p}^{\mathrm{c}}=0.000$ \\
\hline Blastocyst & $1.571 \pm 0.5345^{\mathrm{a}}$ & $3.857 \pm 0.6901^{\mathrm{a}, \mathrm{c}}$ & $1.286 \pm 0.7559^{\mathrm{c}}$ & 0.000 & $\mathrm{p}^{\mathrm{a}}=0.000, \mathrm{p}^{\mathrm{c}}=0.000$ \\
\hline
\end{tabular}

*Data was analysed using oneway anova test

**Data was analysed using Tukey HSD test

$\mathrm{Pa}$ Comparison between control and ketogenic group

$\mathrm{Pb}$ Comparison between control and western group

Pc Comparison between ketogenic and western group

$p$ value of $<0.05$ was considered statistically significant.

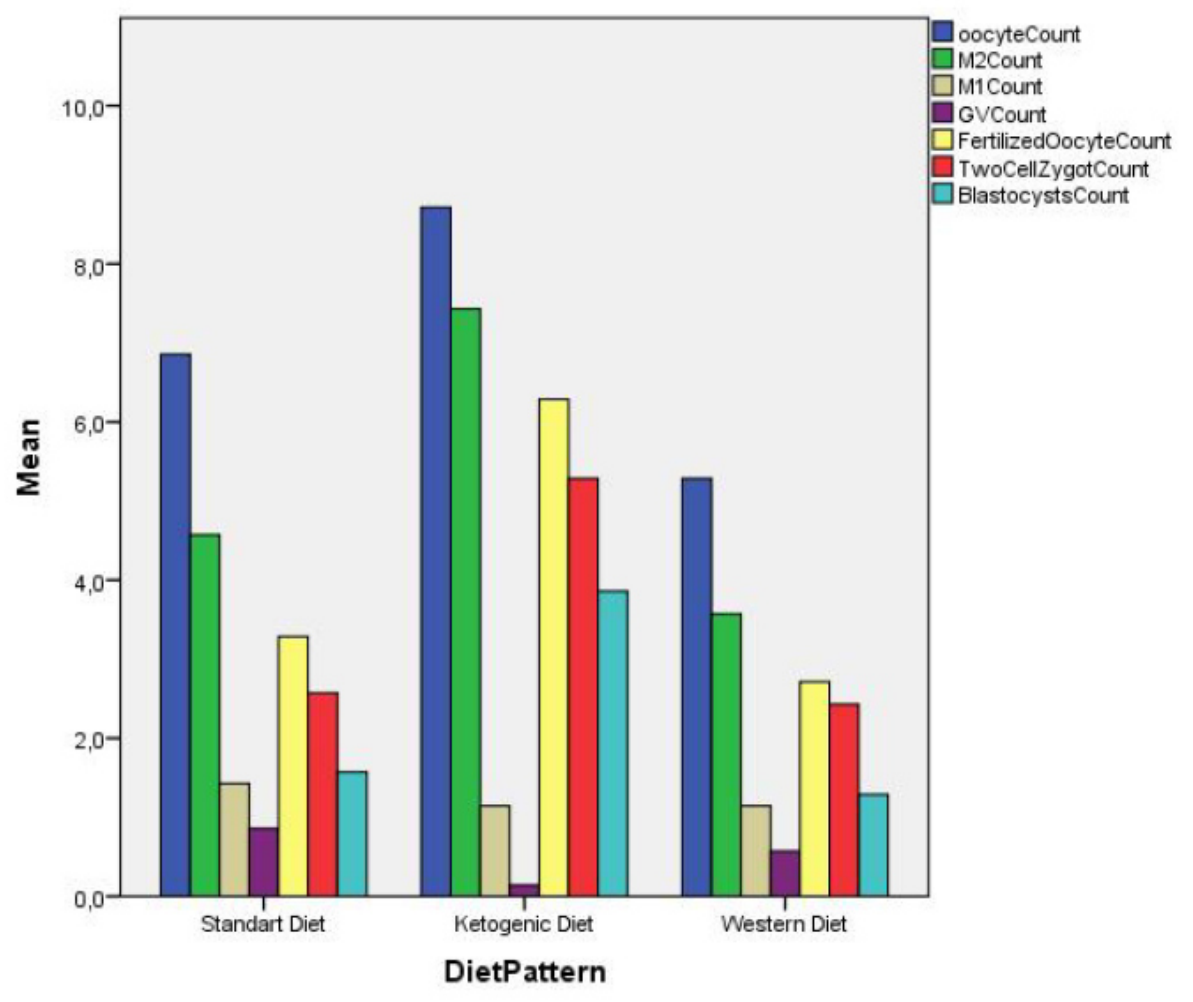

